\title{
An Intertidal Soft-Sediment Avian Exclosure Which Minimizes Sediment Alterations
}

\author{
S. A. Bloom \\ Department of Zoology, University of Florida, Gainesville, Florida 32611, USA
}

Experimental approaches to infaunal community dynamics have commonly involved exclosures, but siltation and increased organic content of the sediment due to alterations in current velocities can cloud the utility and acceptance of data gathered from exclosures in soft-sediment systems (e.g. Woodin, 1974; Virnstein, 1977; Best, 1978). This short note describes a cage with hinged floating sides and covered with $1.27 \mathrm{~cm}$ mesh implanted on a Florida low-energy intertidal sandflat. At low tide, the cage sides hang perpendicular to the sediment and exclude surfaceforaging predators such as birds. At high tide, the sides float in the same plane as the cage roof, are defouled by water currents and do not impede the flow of water over the sediment surface. Quantitative sedimentary data will be presented to support the contention that an appropriate cage design is a useful experimental tool.

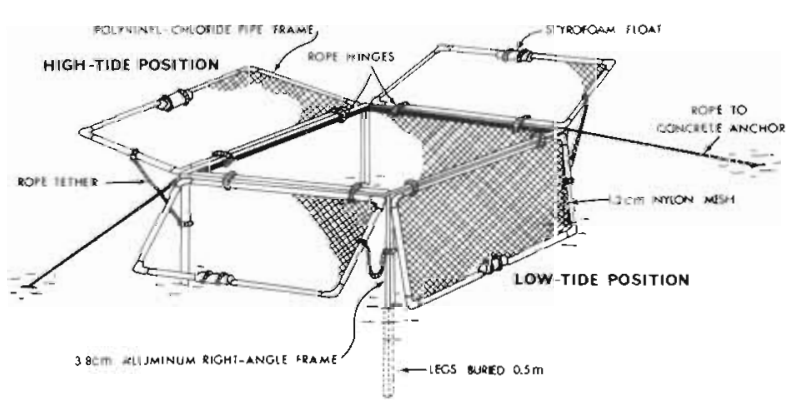

Figure 1. Cage $(1.0 \mathrm{~m}$ on a side) designed to exclude surfaceforaging predators, e. g. birds, while minimizing sediment alterations. Low-tide and high-tide positions are indicated

Construction details of the cage are presented in Figure 1. The implantation site was on a low-energy sandflat $16.3 \mathrm{~cm}$ ( 0.5 feet) above mean tidal level on the Florida Gulf Coast ( $83^{\circ} 04^{\prime}$ West; $29^{\circ} 06^{\prime}$ North). The sandflat was muddy but firm and bordered by extensive Halodule beaudettei (= wrightil) and Thalassia testudinum grassbeds.
An initial set of 5 sediment samples and 5 organic samples were taken on Day 0. Ten sediment samples and 5 organic samples were taken from the cage after 19, 32, 64 and $91 \mathrm{~d}$. Control samples were also taken at the same tidal height and times from the sandflat at approximately $10 \mathrm{~m}$ from the cage. There were 7 sediment samples and 15 organic samples taken except on Day 19 when 10 and 5 samples respectively, were taken. All samples were obtained with a $10 \mathrm{~cm}$ long, $3.8 \mathrm{~cm}$ diameter core and frozen until processed. Sediment samples were wet-sieved using standard procedures (Holme and McIntyre, 1971) and were analyzed by a FORTRAN IV program, SEDANA (Bloom et al., 1977). Organic content was determined by combustion (Byers et al., 1978). The experimental period (July 7 to October 6, 1979) corresponded to the period of maximum release of floating detritus from nearby grassbeds. This period was chosen to maximize the fouling potential. There was no cage maintenance throughout the period.

Sedimentary parameters were calculated using standard equations (Folk, 1966). Mean values, standard deviations and ranges for the 6 parameters are presented in Table 1. To detect changes through time and to test for differences between treatments, a covariance analysis (Sokal and Rohlf, 1969) was used. Regression results are presented in Table 1 and covariance results in Table 2. For 2 of the 6 parameters (mean grain-size and silt/clay percentage), there was no statistical difference between control and experimental samples, i.e. the null hypothesis of coincident regression lines of the 2 parameters to time for the 2 treatments (control and experimental) could not be rejected at the 0.05 level. Regression lines of organic content to time for the 2 treatments were non-coincident, but were uniformly offset by only $0.05 \%$ organic content (control samples averaging less than $10 \%$ more than experimental samples). For the other 3 parameters, 
Table 1. Six sediment characteristics of environmental control and experimental cage samples with preliminary statistical analyses

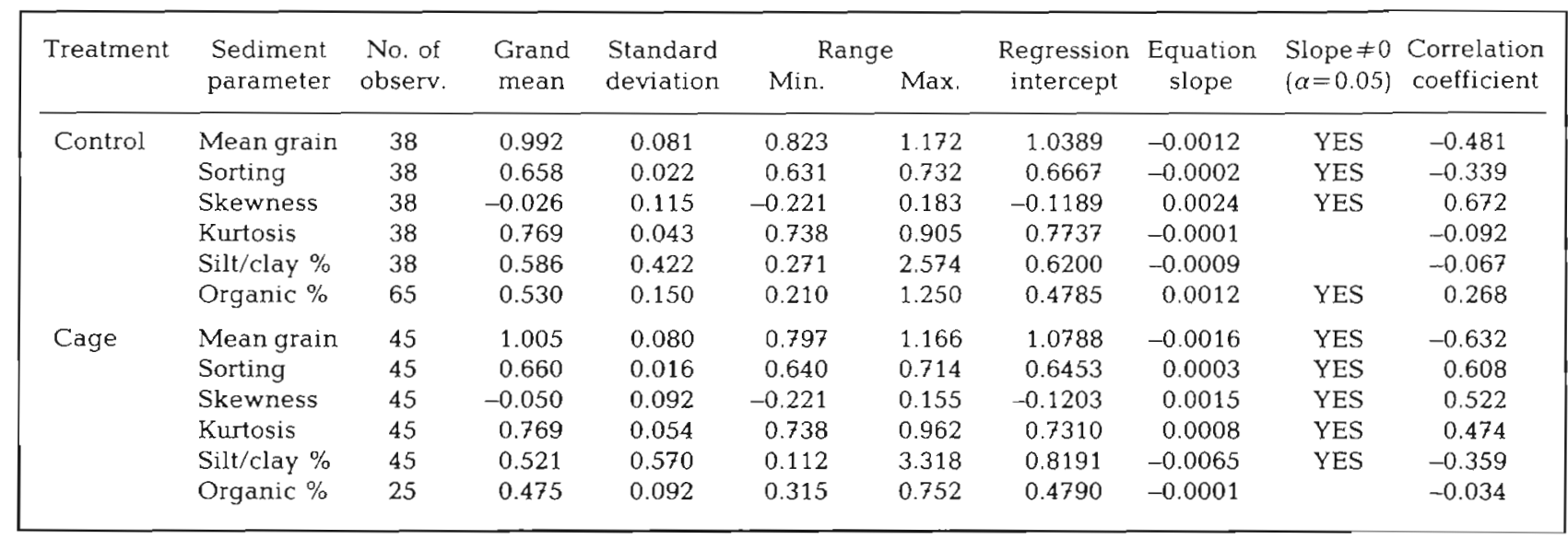

Table 2. Covariance analysis of 6 sediment parameters. Comparsion of regression lines of the parameters to time for environmental control to experimental cage samples at $\alpha=0.05$

\begin{tabular}{lccc|}
\hline Sediment parameter & Coincident regression lines & Parallel regression lines & Number of observations \\
\hline Mean grain size & accept & not applicable & 83 \\
Sorting coefficient & reject & reject & 83 \\
Skewness & reject & reject & 83 \\
Kurtosis & reject & reject & 83 \\
Silt/clay percentage & accept & not applicable & 83 \\
Organic percentage & reject & accept & 88 \\
\hline
\end{tabular}

regression lines to time for the 2 treatments were noncoincident and non-parallel. The biological importance of these statistical differences is debatable. The ranges of sorting and skewness for experimental samples are encompassed by control values. Kurtosis has the same minimum value and the same grand mean for the 2 treatments and the experimental maximum exceeds the control maximum by only 0.052 .

This result of minimal cage effects could be due to a lack of water movement or fouling potential during the experimental period. This is not the case here. A second exclosure (fixed sides of $3 \mathrm{~m} \times 1.2 \mathrm{~m}$ high without top and with $5 \mathrm{~cm} \times 10 \mathrm{~cm}$ mesh) was implanted at the same time and placed as the cage pictured in Figure 1. In 1 week, the large cage was clogged with dead seagrass and a thick algal scum covered the sediment. After $14 \mathrm{~d}$, the cage was bent under the weight of the accumulated decaying vegetation and at least 10 large crabs (Callinectes sapidus) were observed. The rapidity of the onset and the severity of the cage effects in the large fixed cage (even with a mesh size 22 times larger than that of the floating cage) clearly demonstrates that the potential for generating cage effects was present during the experimental period.

One major, and in many cases, valid objection to experimental cages is that changes in populations or sizes of organisms within cages may be due to exclusion of predators or the effects may be due to alterations in physical conditions or the formation of refuges for predators such as crabs (Virnstein, 1977). In many cases, there is no good way to separate these effects, though cages with incomplete sides or tops may serve as partial controls on cage effects. The results presented here clearly demonstrate that for an appropriate cage design, cage effects can be minimal. After $91 \mathrm{~d}$ without maintenance, the biologically important parameters of mean grain-size, silt/clay percentage and organic content were virtually indistinguishable between control and cage samples. It is thus possible to avoid cage effects and to monitor cages for effects during experimental procedures.

The cage design tested here will be of great utility in testing effects of surface-foraging predators which are active at low tides and in separating those effects from predators (fishes, crabs, etc.) which forage when the tide is in. The lack of major cage effects also opens the opportunity to explore effects of infaunal predation by artificially increasing infaunal predator densities within cages. The manipulations can be easily monitored by standard techniques and the effects of altering infaunal predation on community structure, on competitive interactions within the infauna and on vertical 
distributions of the infauna are all possible. By performing such manipulations in caged and non-caged plots, the impact of avian and other low-tide foragers on the dynamics of predation and competition among the infauna can be assessed.

\section{LITERATURE CITED}

Best, B. A. (1978). The effects of suspension feeding by the bivalve Mercenaria mercenaria on community structure. M.A. thesis, University of Florida

Bloom, S. A., Santos, S. L., Field, J. G. (1977). A package of computer programs for benthic community analyses. Bull. mar. Sci. 27: 507-580
Byers, S. C., Mills, E. L., Steward, P. L. (1978), A comparison of methods of determining organic carbon in marine sediments, with suggestions for a standard method. Hydrobiologica 58: 43-47

Folk, R. L. (1966). A review of grain-size parameters Sedimentology 6: 73-93

Holme, N. A., Mclntyre, A. D. (1971). Methods for the study of the marine benthos, Blackwell, Oxford (I.B.P.Handbook No. 16)

Sokal, R. R., Rohlf, F. J. (1969). Biometry, W. H. Freeman and Co., San Francisco

Virnstein, R. W. (1977). The importance of predation by crabs and fishes on benthic infauna in Chesapeake Bay. Ecology 58: $1199-1217$

Woodin, S. A. (1974). Polychaete abundance patterns in a marine soft-sediment environment: the importance of biological interactions. Ecol.Monogr. 44: 171-187 